\title{
Kearifan Lokal Upacara An Tama Masyarakat Adat Loona sebagai Sumber Belajar Geografi
}

\author{
Martinus Hermenegild Mau ${ }^{1}$, Singgih Susilo ${ }^{1}$, I Nyoman Ruja ${ }^{1}$ \\ ${ }^{1}$ Pendidikan Geografi-Universitas Negeri Malang
}

\begin{tabular}{l}
\hline INFO ARTIKEL \\
\hline Riwayat Artikel: \\
Diterima: $17-05-2019$ \\
Disetujui: $14-09-2019$ \\
\hline
\end{tabular}

\section{Kata kunci:}

local wisdom; environmental conservation; geography learning resources, kearifan lokal: pelestarian lingkungan; sumber belajar geografi

\author{
Alamat Korespondensi: \\ Martinus Hermenegild Mau \\ Pendidikan Geografi \\ Universitas Negeri Malang \\ Jalan Semarang 5 Malang \\ E-mail: martinushermenegild@gmail.com
}

\begin{abstract}
The purpose of this study was to examine the values of local wisdom in the An Tama ceremony at the Loona indigenous community as a source of learning Geography. This type of research is qualitative research using an ethnographic approach. Data sources were obtained from observation and interviews of Loona indigenous people's. The results of the study show that during the An Tama ceremony at the Loona indigenous people's established a harmonious relationship with their environment. Community trust in the forces of nature and ancestral spirits causes people to always act carefully in treating their environment. Unconsciously, community trust in the An Tama ceremony is able to preserve the environment. The values of local wisdom need to be known by students, so that it can be used as a source of learning in Geography learning.

Abstrak: Tujuan penelitian ini untuk mengkaji nilai-nilai kearifan lokal dalam upacara An Tama pada masyarakat adat Loona sebagai sumber belajar Geografi. Jenis penelitian ini adalah penelitian kualitatif dengan menggunakan pendekatan etnografi. Sumber data diperoleh dengan melakukan observasi dan wawancara pada masyarakat adat Loona. Hasil penelitian menunjukan bahwa dalam upacara An Tama masyarakat adat Loona menjalin hubungan yang harmonis dengan lingkungannya. Kepercayaan masyarakat terhadap kekuatan alam dan roh leluhur menyebabkan masyarakat selalu bertindak secara hati-hati dalam memperlakukan lingkungannya. Secara tidak sadar kepercayaan masyarakat dalam upacara An Tama mampu menjaga kelestarian lingkungannya. Nilainilai kearifan lokal tersebut perlu diketahui oleh mahasiswa sehingga dapat dijadikan sebagai sumber belajar dalam pembelajaran Geografi.
\end{abstract}

ABSTRAK

Kearifan lokal merupakan bentuk pengetahuan dalam sebuah kelompok masyarakat untuk mengolah dan memanfaatkan lingkungan sekitarnya sesuai dengan tradisi dan kepercayaannya. Salah satu bentuk kearifan lokal dapat tercermin dalam suatu kebudayaan. Menurut (Sukmawaty \& Sugiyono, 2016), kearifan lokal merupakan warisan dari nenek moyang dalam tata nilai kehidupan yang menyatu dalam bentuk religi, budaya dan adat istiadat. Upacara An Tama merupakan sebuah kebudayaan yang menjadi salah satu keunggulan lokal pada masyarakat Suku Bunaq di kabupaten Belu Provinsi Nusa Tenggara Timur. Budaya ini merupakan budaya berburu yang dilakukan sebagai usaha untuk menghalau hama dari usaha pertanian masyarakat. Pelaksanaannya dilakukan melalui serangkaian upacara ritual secara adat. Mitos dan kepercayaan masyarakat setempat bahwa alam dan roh leluhur memiliki kekuatan supernatural yang dapat memberikan rezeki dan juga malapetaka bagi mereka. Kepercayaaan ini menjadi bentuk kearifan lokal sehingga manusia selalu bertindak secara hati-hati dalam berinteraksi dengan lingkungannya. (Sufia, Sumarmi, \& Amirudin, 2016) menjelaskan bahwa kearifan lokal merupakan bagian dari masyarakat agar dapat bertahan hidup sesuai dengan kondisi lingkungan, sesuai dengan kebutuhan, dan kepercayaan yang telah mengakar dan sulit untuk dihilangkan.

Bentuk kearifan lokal yang tercermin dalam budaya An Tama diartikulasikan melalui cara menghalau hama melalui mitos-mitos yang dipercayai dan praktik berburu yang dilaksanakan oleh masyarakat secara turun-temurun. Kearifan tersebut mengandung nilai pelestarian lingkungan hidup, yakni adanya aturan-aturan adat, adanya hutan yang dikeramatkan oleh masyarakat, serta sistem perburuan yang dilaksanakan menggunakan peralatan yang sederhana dan waktu pelaksanaannya dilakukan sekali dalam setahun. Secara tidak langsung, kebiasaan tersebut menjadi bentuk kearifan lokal dalam menjaga kelestarian lingkungan hidup. (Pattiselanno \& Mentansan, 2011) berpendapat bahwa kearifan tradisional/lokal bisa dalam bentuk hukum, pengetahuan, keahlian, nilai dan sistem sosial dan etika yang hidup dan berkembang dari satu generasi ke generasi berikutnya. 
Proses interaksi antara manusia dan lingkungan yang terwujud dalam budaya An Tama merupakan bentuk dari adaptasi manusia terhadap lingkungannya. Hal ini dipengaruhi oleh kondisi geografis daerah dan keadaan alam sekitar yang memengaruhi kehidupan manusia. Adanya hama yang berada di sekitar masyarakat dianggap sebagai organisme pengganggu tanaman yang dapat merugikan para petani menyebabkan budaya An Tama lahir sebagai bentuk adaptasi manusia. Menurut (Bintarto, 1983; Sadilah, Mudjijono, Budi, \& Silistyo, 2015) budaya menjadi wujud dari bentuk adaptasi atau penyesuaian manusia terhadap lingkungannya, baik secara secara fisik maupun sosial budaya.

Interaksi dan interdependensi antara komponen-komponen lingkungan hidup (unsur fisik, hayati dan budaya) dapat menimbulkan kerusakan lingkungan. Kerusakan lingkungan hidup tersebut dapat disebabkan karena tindakan manusia maupun kejadian alam. Salah satu contoh kerusakan lingkungan adalah tindakan perburuan yang tidak terkontrol sehingga akan berdampak menurunya keanekaragaman hayati. (Wulandari, Dwijanto, \& Sunarmi, 2015) menyatakan bahwa semakin menurunnya keanekaragaman hayati sebagai akibat dari perubahan lingkungan yang berasal dari kegiatan manusia, pemukiman, perusakan hutan dan perluasan area pertanian. Artinya, kerusakan lingkungan hidup itu dapat disebabkan oleh sikap dan perilaku manusia terhadap lingkungannya. Realita yang terjadi pada masyarakat adat Loona Suku Bunaq ini adalah manusia dengan pengetahuan lokalnya melalui sitem kepercayaan mereka mengelola lingkungannya secara bijaksana. Masyarakat melakukan perburuan dengan berdasarkan pada kepercayaan dan aturan-aturan adat yang berlaku.

Budaya An Tama yang terdapat pada masyarakat adat Loona Suku Bunaq menjadi sebuah kearifan lokal yang mengandung nilai-nilai kepedulian lingkungan yang dapat diintegrasikan ke dalam pembelajaran Geografi. Mahasiswa atau peserta didik sebagai agen penerus bangsa perlu mengetahui kebudayaan yang dimilikinya. Nilai-nilai yang terdapat dalam sebuah kebudayaan akan membentuk sikap dan karakter menjadi manusia yang arif dalam mengelola lingkungan serta membantu menemukan cara menyelesaikan masalah-masalah kehidupan. Oleh sebab itu, mengintegrasikan nilai-nilai budaya dalam dunia pendidikan menjadi hal sangat penting. Joesoef (1982, (Jamal, 2017) menyatakan bahwa nilai-nilai budaya merupakan landasan karakter bangsa penting ditanamkan pada setiap individu sehingga mampu memahami, memaknai, dan menghargai pentingnya nilai budaya dalam menjalankan aktivitas kehidupan.

Pembelajaran Geografi tidak hanya berperan sebagai ilmu pengetahuan untuk menjadikan peserta didik yang berkualitas dari sisi kognitif, melainkan juga perlu membentuk sikap dan perilaku. Sikap dan perilaku peserta didik dapat terbentuk dengan mengintegrasikan nilai-nilai kebudayaan yang ada pada masyarakat. Oleh karena itu, dalam pembelajaran perlu adanya kesesuaian materi dengan kondisi dan fenomena lokal. (Syarif, Sumarmi, Fatchan, \& Astina, 2016) menyatakan bahwa dalam teori behaviorisme, perilaku manusia itu dibentuk oleh hasil dari pengalaman dan peran lingkungan. Sikap dan perilaku peserta didik dapat terbentuk sebagai keunggulan dari suatu budaya lokal masyarakat setempat maupun kondisi geografis tertentu suatu wilayah. (Sukmawati, Utaya, \& Susilo, 2015) mengatakan bahwa melalui pengalaman belajar, mahasiswa akan mewarisi nilai luhur suatu budaya dan melembagakan nilai tersebut dalam dirinya. Oleh sebab itu, perlunya pembelajaran Geografi yang kontekstual. Melalui pengalaman belajarnya mahasiswa/peserta didik dapat mewarisi nilai-nilai budaya yang dapat membentuk sikap mahasiswa/peserta didik untuk peduli dan berperilaku arif terhadap lingkungannya.

\section{METODE}

Penelitian ini merupakan jenis penelitian kualitatif dengan menggunakan pendekatan etnografi. Kerja lapangan, Etnografer dalam membuat suatu kesimpulan kebudayaan berdasarkan tiga sumber, yakni (1) dari apa yang dikatakan orang, (2) dari cara orang bertindak, dan (3) dari berbagai artefak yang digunakan orang, (Spradley, 2007). Sumber data diperoleh dari informan kunci yaitu Ama Nai Loona selaku Kepala Adat dan Teri Gomo selaku pelaksana dalam upacara An Tama, sedangkan informan pendukung lainnya adalah budayawan, kepala desa, dan masyarakat adat. Teknik pengumpulan data dilakukan dengan cara melakukan observasi, wawancara, dan dokumentasi.

\section{HASIL DAN PEMBAHASAN}

\section{Proses Pelaksanaan Budaya An Tama}

Budaya An Tama dilaksanakan atas dasar kepercayaan masyarakat adat Loona terhadap roh alam dan leluhur. Masyarakat mempercayai bahwa apa yang mereka lakukan selalu berkaitan dengan kekuatan supernatural dari alam dan roh leluhur sehingga masyarakat selalu bertindak secara hati-hati dalam berinteraksi dengan lingkungannya. Sistem kepercayaan ini menjadi mitos yang terus digenerasikan secara turun temurun sehingga dapat menjadi kearifan dalam menjalin hubungan antara manusia dengan lingkungannya. (Manuaba, Dewi, \& Kinasih, 2012) menyatakan bahwa mitos memiliki relasi dan korelasi yang kuat dalam menjaga kelestarian hutan karena berkat keyakinan pada mitos itulah, masyarakat adat tergerakkan kesadarannya untuk menunjukkan sikap bersahabat dengan kehidupan flora dan fauna.

Budaya An Tama yang hadir di tengah masyarakat adat Loona dipengaruhi oleh kondisi geografis wilayahnya. Temuan di lapangan mengungkapkan bahwa kawasan adat Loona merupakan daerah perbukitan yang terdapat sabana dan hutan yang menjadi habitatnya satwa liar. Pandangan masyarakat sekitar bahwa satwa liar merupakan hama bagi usaha pertanian masyarakat, sehingga dengan pengetahuan lokal, masyarakat berupaya untuk mengatasi permasalahan lingkungannya. Hal ini kemudian 
ditradisikan hingga menjadi sebuah kebudayaan. (Kaplan \& Manners, 2012) menyatakan bahwa proses pembentukan sebuah budaya ada keterkaitannya dengan karakteristik ekologi yang memengaruhi masyarakat. Hasil temuan di lapangan mengungkapkan Budaya An Tama yang dilakukan oleh masyarakat adat Loona dilaksanakan melalui bebarapa proses. Prosesi pelaksanaan yang dilakukan tidak terlepas dari kepercayaan mereka terhadap leluhur dan kekuatan alam gaib, berikut jabarannya:

1. Tahapan Persiapan

a. Peneliti mengungkapkan bahwa pada tahapan persiapan yang dilakukan dalam prosesi pelaksanaan Budaya $A n$ Tama dilaksanakan dengan melakukan ritual acara Hoto Boto Hosok. Acara Hoto Boto Hosok dilakukan dengan berbagai macam tindakan.

b. Penyembelihan ayam, dimaksudkan untuk meramalkan baik dan buruknya kegiatan yang akan dilaksanakan serta meramalkan ada atau tidak adanya bencana pada usaha pertanian.

2. Tahapan Pelaksanaan

Prosesi pelaksanaan Budaya An Tama pada tahapan ini dilakukan melalui beberapa rangkaian acara.

a. Ritual Acara An Por, yaitu acara "pembersihan jalan". Acara ini disimbolkan dengan tindakan pembakaran semak. Maksud dari tindakan ini agar perburuan yang dilaksanakan bebas dari gangguan roh jahat.

b. Ritual Acara Mun Leu, yaitu acara pengurungan hewan buruan. Acara ini disimbolkan dengan tindakan mengikat pohon beringin menggunakan tali hutan. Maksud dari tindakan ini agar hewan buruan yang akan diburu tidak dapat keluar dari hutan tempat perburuan dilaksanakan.

c. Ritual Acara Heruk Hone, yaitu acara "pembersihan diri”. Acara ini disimbolkan dengan tindakan membuang duri yang diludahi pemburu ke arah terbenamnya matahari.

d. Ritual Acara An Tama, yaitu acara berburu. Acara ini dilakukan dengan melakukan perburuan hewan yang dianggap sebagai hama. Tindakan ini dimaksudkan agar hama yang diburu tidak lagi mendekat dan mengganggu usaha pertanian masyarakat.

e. Ritual Acara Tun Tapi, yaitu acara makan berburu. Acara ini dilakukan dengan cara makan hewan hasil buruan bersama sambil berdiskusi tentang kegiatan perburuan yang telah dilaksanakan.

f. Ritual Acara Por Mit, yaitu acara "duduk pemali". Acara ini disimbolkan dengan tindakan duduk berdiam pada malam hari sampai pagi hari tanpa adanya cahaya dan suara. Maksud dari tindakan ini agar usaha pertanian yang dilakukan masyarakat dirahasiakan dari hama.

g. Ritual Acara Hos Gak, yaitu acara memilah makan kepada hewan yang dianggap sebagai hama. Acara ini dilakukan dengan cara mengucapkan mantra dan memberikan bagian makanan kepada hama. Maksud tindakan ini agar hama tidak lagi mengganggu usaha pertanian masyarakat.

h. Ritual Acara Lata Rasa, yaitu acara pembersihan induk kebun. Acara ini disimbolkan dengan pembersihan batu yang disebut beki. Beki ini sebagai penanda identitas suku rumah sebagai induk kebunnya. Maksud dari tindakan ini agar lahan usaha pertanian masyarakat tidak dibersihkan secara terus menerus.

i. Ritual Acara Tubi Lai, yaitu acara pemberian sesaji kepada leluhur. Tindakan ini dimaksudkan agar masyarakat selalu diberkati oleh arwah leluhur mereka.

\section{Kearifan Lokal Masyarakat Adat Loona}

Setiap tahapan dalam prosesi pelaksanaan Budaya An Tama selalu dilakukan berdasarkan sistem kepercayaan masyarakat. Hal ini menjadi kearifan lokal bagi masyarakat adat Loona dalam memperlakukan lingkungannya. Adanya aturan adat, pantangan dan kepercayaan masyarakat bahwa lingkungan alam memiliki kekuatan supernatural menyebabkan masyarakat selalu bertindak bijaksana dalam memperlakukan lingkungannya. (Sufia et al., 2016) menjelaskan bahwa kearifan lokal merupakan bagian dari masyarakat untuk bertahan hidup sesuai dengan kondisi lingkungannya, sesuai dengan kebutuhan, dan kepercayaan yang telah berakar dan hal itu sulit untuk dihilangkan.

Budaya An Tama pada masyarakat adat Loona dilaksanakan sekali dalam waktu satu tahun. Temuan peneliti mengungkapkan bahwa waktu pelaksanaan Budaya An Tama tidak memiliki tanggal dan bulan yang tetap. Penentuan waktu pelaksanaan Budaya An Tama berdasarkan ketika musim hujan terjadi. Hal ini disebabkan karena budaya An Tama yang dilaksanakan dalam rangka mempersiapkan lahan pertanian untuk menyambut musim tanam. Berdasarkan selang waktu pelaksanaanya, secara tidak langsung satwa liar yang diburu diberikan kesempatan untuk berkembang biak. Artinya, budaya An Tama secara tidak langsung dapat menjadi kearifan lokal dalam mengonservasi satwa liar di wilayahnya.

Pemahaman masyarakat mengenai terdapat kekuatan lain yang memengaruhi kehidupan mereka memberikan konsep bahwa mereka tidak hidup sendirian, namun selalu berdampingan bersama lingkungan alam. Anggapan masyarakat bahwa hutan, gunung, lembah, dan roh leluhur memiliki kekuatan supernatural yang dapat memberikan rejeki dan juga bencana. Pandangan ini menyebabkan kehidupan mereka senantiasa selalu hidup berdampingan dengan lingkungan alam. Secara tidak langsung 
masyarakat adat Loona berusaha agar tetap menjaga kelestarian lingkungan sekitarnya. Pandangan dengan sikap hidup seperti ini dapat menciptakan keselarasan hubungan antara manusia dengan alam. (Daeng, 2000) menyatakan bahwa kekuatan supranatural memberikan pedoman bagi manusia untuk bertindak secara bijaksana.

Masyarakat adat Loona memandang hutan sebagai tempat yang sakral dan memilki kekuatan mistis yang dapat memberikan bencana bagi yang mengambil sumber daya alamnya secara ilegal. Kepercayaan masyarakat setempat bahwa hutan menjadi tempat persinggahan arwah para leluhur sehingga hutan dijadikan sebagai tempat melakukan berbagai upacara ritual adat. Menurut informan, hutan yang disakralkan lebih ditakuti masyarakat karena memiliki kekuatan gaib yang dapat memberikan malapetaka. Kepercayaan ini menjadi pedoman bagi masyarakat untuk tetap menjaga agar hutannya tetap lestari sehingga dapat mencegah terjadinya kerusakan lingkungan.

Perilaku lain yang menunjukkan masyarakat adat Loona bersikap ramah terhadap lingkungannya dibuktikan melalui peralatan yang sederhana dalam melakukan perburuan. Panah, tombak, dan sumpit adalah peralatan yang digunakan oleh masyarakat adat Loona dalam melakukan perburuan. Masyarakat tidak memiliki pengetahuan lingkungan dalam menggunakan peralatan dalam berburu. Namun, masyarakat memandang bahwa alat sederhana yang digunakan merupakan warisan leluhur yang harus dijaga dan digunakan dalam kegiatan ritual adat. Pemahaman mereka yang sederhana menyebabkan masyarakat setempat tidak merusak lingkungan alam mereka dengan menggunakan peralatan yang modern.

Berkaitan dengan pelestarian lingkungan, lembaga masyarakat adat Loona juga memiliki aturan dan sanksi adat yang membatasi perlakuan masyarakat terhadap lingkungannya. Peraturan adat ini dikenal pada masyarakat adat Loona dengan sebutan ukon. Berikut ini adalah Ukon (aturan adat) dalam pelestarian lingkungan pada masyarakat adat Loona.

1. Semua hewan peliharaan harus dikandangkan dan apabila dikeluarkan dari kandang wajib diikat di kebun.

a. Apabila hewan tidak dikandangkan dan merusak tanaman maupun tumbuh-tumbuhan lain di lahan orang lain pada malam hari maka hewan tersebut dapat dibunuh dan diatur sesuai adat yang berlaku, sedangkan kerugian tanaman tetap dibayar kepada pemilik tanaman sesuai kesepakatan.

b. Apabila hewan diikat atau dilepas pada lahan orang lain dikenakan sanksi, membayar Rp. 250.000 (Dua ratus lima puluh ribu) kepada penangkap hewan, membayar harga hasil/tanaman yang dirusak kepada pemilik tanaman, dan apa golu (membunuh sapi) atau didenda satu ekor babi besar ditambah lima botol sopi.

2. Peraturan pemanenan hasil kebun (Koso Jobel) mengenai berbagai tanaman seperti, mangga, pisang, jagung, padi, pinang, kelapa, pepaya, ubi-ubian, rumput gajah, daun gala-gala atau daun pohon lain untuk pakan ternak dikenakan sanksi satu ekor babi dan lima botol sopi.

3. Kemiri apabila ada orang yang memungut hasil kemiri atau bawang milik orang lain dikenakan sanksi satu ekor babi besar ditambah sopi satu dos. Jika tidak ada babi diganti dengan uang sebesar Rp. 2. 500.000.

4. Mengenai Cendana, apabila seseorang dengan sengaja memotong cendana di dalam wilayah Kenaian Loona atau kelalaiannya cendana terbakar maka dikenakan sanksi, satu ekor babi/Rp. 2.500.000, satu dos sopi, uang Rp. 250.000, satu lembar kain adat.

5. Hutan dan Sumber Air. Bagi siapapun yang menebang pohon, bambu, atau enau di dalam hutan adat atau hutan yang bersumber air yang sudah terlarang sejak leluhur atau hotorene por sobo/pemulihan hutan dan sumber air dikenakan sanksi, satu ekor babi besar, lima botol sopi, sepuluh kg beras, dan menanam 100 anakan pohon baru di tempat tersebut, dibawah pengawasan Kapitan dan Makleat.

Ukon (aturan adat) yang terdapat pada masyarakat adat Loona tersebut memberikan batasan pada masyarakat agar selalu bertindak hati-hati terhadap lingkungannya. (Agus Effendi, 2012) menyatakan bahwa tabu berfungsi sebagai pengendali segala aktivitas manusia yang berhubungan dengan lingkungannya. Ketaatan manusia pada aturan-aturan yang diwariskan secara turun temurun menjadikan kelestarian lingkungannya tetap terjaga.

\section{Kearifan Lokal Budaya An Tama sebagai Sumber Belajar Geografi}

Budaya An Tama yang terdapat pada masyarakat adat Loona dapat mengisi kebutuhan materi pembelajaran Geografi menjadi kontekstual. Buku suplemen bahan ajar dapat dijadikan alternatif bagi guru/dosen untuk memaparkan materi secara mendalam yang relevan pada peserta didik. Melalui suplemen bahan ajar, guru/dosen dapat mengaitkan materi yang diajarkan sehingga dapat menciptakan pembelajaran yang nyata/kontekstual. Dengan kata lain, membawa dunia luar ke dalam kelas.

Matakuliah Geografi Lingkungan dan Sumber Daya Alam mengkaji konsep pendekatan, kebijaksanaan pengelolaan sumber daya alam, manusia, dan lingkungan serta pengaruhnya terhadap lingkungan, dan menentukan kebijaksanaan dalam memanfaatkan sumber daya alam yang tepat. Oleh sebab itu, nilai-nilai budaya An Tama yang telah dikaji dapat diintegrasikan dalam pembelajaran Geografi sehingga dpat menumbuhkan sikap arif dan bijak, serta sikap peduli lingkungan pada diri mahasiswa. 


\section{SIMPULAN}

Masyarakat adat Loona secara turun temurun telah melaksanakan Budaya An Tama sebagai wujud dari interaksi antara manusia dengan lingkungannya. Budaya An Tama yang dilaksanakan mengandung nilai-nilai kearifan lokal dalam menjaga kelestarian lingkungan hidup. Nilai kearifan ini terwujud dalam bentuk perilaku manusia dalam memperlakukan alam sesuai dengan kepercayaan, penggunaan peralatan sederhana dalam berburu, pandangan masyarakat terhadap hutan, dan aturan-aturan adat yang mengendalikan sikap masyarakat terhadap lingkungannya. Nilai-nilai kearifan lokal dalam budaya An Tama penting diketahui oleh mahasiswa dan dapat dijadikan sebagai sumber belajar Geografi sehingga nilai-nilai tersebut dapat menumbuhkan sikap arif, bijak, dan peduli terhadap lingkungan. Kearifan lokal budaya An Tama disarankan agar dapat dijadikan sebagai sumber belajar Geografi sehingga pembelajaran menjadi lebih kontekstual dan kelestarian budaya tetap terjaga.

\section{DAFTAR RUJUKAN}

Agus Effendi, S. (2012). Implementasi Kearifan Lingkungan Dalam Budaya Masyarakat Adat Kampung Kuta sebagai Sumber Pembelajaran IPS. Diakses dari http://jurnal. upi. edu/file/17-AGUS_EFFENDI-edit. pdf.

Bintarto, R. (1983). Interaksi Desa-Kota dan Permasalahannya. Jakarta: Ghalia Indonesia.

Daeng, H. (2000). Manusia, Kebudayaan, dan Lingkungan: Tinjauan Antropologis. Pustaka Pelajar.

Jamal, S. (2017). Pengaruh Motivasi Belajar terhadap Prestasi Belajar IPS Siswa Kelas VIII SMPN 2 Srumbung. Social Studies, 6(4), 469-479.

Kaplan, D., \& Manners, R. A. (2012). La relación entre la teoría etnológica y el hecho etnográfico. Antropología y Comparación Cultural: Métodos y Teorías, 335-356. UNED, Universidad Nacional de Educación a Distancia.

Manuaba, I. B. P., Dewi, T. K. S., \& Kinasih, S. E. (2012). Mitos, Masyarakat Adat, dan Pelestarian Hutan. Atavisme, 15(2), 235-246. https://doi.org/https://doi.org/10.24257/atavisme.v15i2.63.235-246

Pattiselanno, F., \& Mentansan, G. (2011). Kearifan Tradisional Suku Maybrat dalam Perburuan Satwa sebagai Penunjang Pelestarian Satwa. Hubs-Asia, 10(1). https://doi.org/https://doi.org/10.7454/mssh.v14i2.664

Sadilah, E., Mudjijono, M., Budi, N., \& Silistyo, S. (2015). Etnografi Masyarakat Desa Randualas (Kajian Budaya SantetanJagong). Yogyakarta: Balai Pelestarian Nilai Budaya (BPNB).

Spradley, J. P. (2007). Etnografi. Yogyakarta: Triwacana.

Sufia, R., Sumarmi, S., \& Amirudin, A. (2016). Kearifan Lokal Dalam Melestarikan Lingkungan Hidup (Studi Kasus Masyarakat Adat Desa Kemiren Kecamatan Glagah Kabupaten Banyuwangi). Jurnal Pendidikan: Teori, Penelitian, dan Pengembangan, 1(4), 726-731.

Sukmawati, S., Utaya, S., \& Susilo, S. (2015). The Local Wisdom of Indigenous People on Forest Preservation as Learning Source of Geographic Subject. Jurnal Pendidikan Humaniora, 3(3), 202-208.

Sukmawaty, W. E., \& Sugiyono, S. (2016). Pengembangan Model Manajemen Unit Produksi SMK Program Studi Keahlian Tata Busana di Kabupaten Sleman. Jurnal Pendidikan Vokasi. https://doi.org/10.21831/JPV.V6I2.7793

Syarif, E., Sumarmi, S., Fatchan, A., \& Astina, I. K. (2016). Integrasi Nilai Budaya Etnis Bugis Makassar Dalam Proses Pembelajaran sebagai Salah Satu Strategi Menghadapi Era Masyarakat Ekonomi Asean (MEA). Jurnal Teori dan Praksis Pembelajaran IPS, 1(1), 13-21.

Wulandari, N. C., Dwijanto, D., \& Sunarmi, S. (2015). Pembelajaran Model REACT. Jurnal Pendidikan Matematika, 4(3). 